\title{
0 uso do solo na Amazônia
}

Observando a cobertura vegetal da Amazônia, verifica-se facilmente que o número de indivíduos e também o número de espécies por hectare atingem cifras surpreendentemente altas. E evidente a existência de condiçōes excepcionalmente favoráveis à manutenção da vida vegetal.

Por outro lado, a avaliação analítica dos solos da Amazônia e a experiência com culturas tradicionais levaram à conclusäo de que os solos da regiāo seriam pobres e inadequados à agricultura.

A contradição é chocante: um solo com capacidade inigualável para o suporte da vida vegetal apontado como solo inadequado à agricultura.

A Ecologia, ciência moderna e em fase de desenvolvimento poderá elucidar a contradição. Já é lícito considerar o solo, com suas propriedades físico-químicas, como um componente de um eco-sistema. Importante, no caso da agricultura, mas sempre apenas um dos componentes, de cujas Interaçōes depende o resultado do eco-sistema. Avulta assim a importância dos outros fatores ambientais.

Afirmar a fertilidade de uma régiăo baseando-se exclusivamente nas qualidades de um componente do eco-sistema talvez seja decisão apressada e sujeita a um enfoque imperfeito.

Tratando-se de um eco-sistema tão pouco conhecido na sua intimidade e tão diverso nas condições encontradas nos climas temperados, considerar-se-ia discutível a validade će conclusões decorrentes da aplicação de critérios de avaliação desenvolvidos para os climas temperados ou baseados em ensaios feitos com sementes longamente melhoradas para climas temperados e com manejo aprimorado durante decênios para climas temperados.

As férteis planícies da Ucrânia não são consideradas pobres e, no entanto, não produzem juta e mandioca. Ninguém classificaria como pobres as terras-roxas do Paraná que não produzem pacovã e cupuaçu. As terras do Middle West americano não poderão ser classificadas como pobres em virtude de nāo produzirem guaraná e seringueiras.

As terras da Amazônia não poderão ser classificadas como pobres por năo produzirem milho, trigo e batatas.

Na realidade, existe na Amazônia um conjunto de fatores excepcionalmente favorável ao suporte da vida vegetal, fatores que ainda não são suficientemente conhecidos nem aproveitados em benefício da agricultura.

O Instituto Nacional de Pesquisas da Amazônia não se dedica à pesquisa agrícola. Mas se aplica a fundo na análise do eco-sistema amazônico, reunindo dados que, associados a informaçōes de outros colegas, constituirão paulatinamente um mosaico de conhecimentos básicos sobre o eco-sistema amazônico, mosaico onde a agronomia encontrará informações que the permitirão equacionar o uso do solo da Amazônia conforme a realidade ecológica. 
A.o iniciar o Vol. 3 de ACTA AMAZONICA, é oportuno rever o que foi publicado nesta revista sobre os fatores ambientais na Amazônia.

Em 1971, dois suplementos do $n .^{\circ} 1$ apresentaram estudos sobre a temperatura do solo, na floresta e em capoeira, estudos pioneiros e sistemáticos durante todo um ano. Trabalhos de W. L. F. Brinkmann com a cooperação do National Center for Atmospheric Research de Boulder, Colorado, que colaborou com a computação dos dados.

Ainda de Brinkmann e seus colaboradores no setor de Ciências do Ambiente do INPA, foram os estudos sobre as temperaturas do ar, com uma observação também pioneira da "friagem", observação acompanhada de dados fornecidos pela meteorologia via satélite. O setor de Ciências do Ambiente publicou no $n .^{\circ} 2$ do Vol. 1 estudos sobre a composição espectral da luz em diversos tipos de floresta. No $n .^{\circ} 3$, outro trabalho notável sobre a temperatura do ar próximo à superficie do solo em diferentes condiçōes de utilização. Em 1972 foram publicadas outras pesquisas originais e pioneiras no setor de Ciências do Ambiente, relacionadas com a circulação da água no solo, a distribuição da luz na intimidade da água de um lago, e a concentração isotópica das águas dos rios Negro e Amazonas.

Continua a coleta e análise de dados climatológicos, estando em vias de conclusão trabalho para o qual foram processados, em 1972, nada menos de 600.000 dados obtidos em diversas estações do INPA. São ainda dignos de registro os trabalhos de W. Rodrigues e cols. sobre a produção de litter e os seus dados, a ser publicados, sobre a regeneração natural da floresta amazônica.

Acrescentando-se as novas espécies descritas por W. Rodrigues, B. P. Albuquerque e M. Freitas da Silva, os trabalhos publicados por Schmidt, Volpato e Araújo sobre o comportamento silvicultural de essências amazônicas, os dados ainda não publicados de Schubart sobre os microartrópodos do solo envolvidos na decomposição do litter e os estudos de B. Cavalcante e de O. M. Fonseca sobre os fungos envolvidos na decomposição do litter e no ciclo de nutrientes, verifica-se que, no INPA, existe um trabalho constante e produtivo no sentido de contribuir para a compreensão do eco-sistema amazônico. Em 1973, serão ainda publicados os primeiros dados sobre ciclagem de nutrientes no solo florestal.

Da soma de informações fornecidas pela pesquisa básica irăo surgir dados úteis para a compreensão da ecologia florestal e para a definição, pela agronomia, das espécies a ser cultivadas com sucesso e do manejo recomendável para o bom rendimento.

Cada dia é mais evidente a necessidade de acelerar as pesquisas sobre a Ecologia Florestal na Amazônia.

\title{
O EDITOR
}

\author{
Editor Responsável: P. Almeida Machado \\ INPA, Manaus - AM
}

